\title{
Degradabilidade "in situ" da fibra do bagaço de cana-de- açúcar tratado com soluções alcalinas e da proteína do farelo de algodão, em bovinos fistulados
}

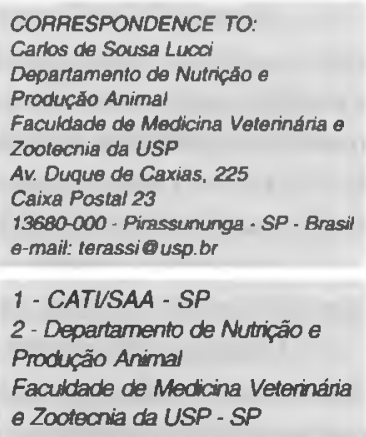

CORRESPONDENCE TO:

Carlos de Sousa Luco

Departamento de Nutriçáo

Produçáo Animal

Caixa Postal 23

e-mail: terassi usp.b

Produção Animal

$\theta$ Zootecria da USP - SP

\author{
Sylvia SONKSEN'; Carlos de Sousa LUCCI²; Iaércio MEL.OTTI²
}

\section{RESUMO}

Foram utilizados quatro bovinos, mestiços europeu/zebu com peso médio de $150 \mathrm{~kg}$, dotados de cânulas ruminais, para estimar as taxas de degradabilidade in situ da matéria seca e da fibra em detergente neutro, do bagaço de cana-de-açúcar, bem como da matéria seca e da proteína bruta do farelo de algodão. Foram comparados quatro tratamentos: A- Bagaço de cana-de-açúcar tratado por imersão em água ( $\mathrm{pH}=6,5)$ e mistura de concentrados contendo tampões; B- Bagaço de cana-de-açúcar tratado com água e mistura de concentrados (controle); C- Bagaço de cana-de-açúcar tratado com solução a 30\% de cinza de madeira (pH = 11,0$)$ e mistura de concentrados; D- Bagaço de cana-de-açúcar tratado com soluçāo a $2 \%$ de hidróxido de sódio $(\mathrm{pH}=11,5)$ e mistura de concentrados. O delineamento foi o quadrado latino $(4 \times 4)$ e os seguintes resultados foram obtidos: a degradabilidade da matéria seca do bagaço de cana-de-açúcar foi maior para o tratamento $\mathrm{D}$, bem como para a fibra em detergente neutro, porém, neste caso, nos tempos de incubação 72 h e 96 h. O farelo de algodão apresentou degradabilidades da matéria seca e da proteina bruta iguais em todos os tratamentos. $O$ tratamento $D$ foi eficiente para aumentar a degradabilidade ruminal do bagaço da cana-de-açúcar

UNITERMOS: Digestibilidade; Soluções; Alcalino; Farelo de algodão; Bagaço de cana-de-açúcar; Bovinos.

\section{INTRODUÇÃO}

egundo Paturau ${ }^{23}$ (1981), o bagaço de cana-de-açúcar (BCA) apresenta $42 \%$ de celulose, $29,4 \%$ de hemicelulose e $20,2 \%$ de lignina; Boin et al. ${ }^{4}$ (1987) também chamam a atenção para o seu elevado teor de lignina (10\% a 20\%). Trabalhos como os de Lamas et al. ${ }^{14}$ (1979); Kumar et al. ${ }^{13}$ (1982); Ibrahin; Pearce ${ }^{9}$ (1983) e Molina et al..$^{17}$ (1983) mostraram dados da composição química do BCA de $1,1 \%$ a $3,3 \%$ para proteína bruta (PB), $2 \%$ a $5,9 \%$ para matéria mineral (MM), $84 \%$ a $94,6 \%$ para fibra em detergente neutro (FDN) e $58 \%$ a $68 \%$ para fibra em detergente ácido (FDA). $\mathrm{O} \mathrm{NRC}^{21}$ (1988) fornece $46,6 \%$ de matéria seca (MS), 1,5\% PB, 49\% FB e $5,5 \%$ de cinzas. Nicholson ${ }^{20}$ (1984) relatou teores de nutrientes digestíveis totais (NDT) de $26 \%$ a $46 \%$.

Com relação aos mecanismos de ação dos tratamentos alcalinos em alimentos fibrosos, Jackson ${ }^{10}$ (1977), Morris; Bacon ${ }^{19}$ (1977) e Chesson; Orskov ${ }^{7}$ (1984), descrevem que são alterações que ocorrem na composição e na organização da parede celular, solubilizando parcialmente a hemicelulose, lignina e sílica.

Carmona; Greenhalgh ${ }^{6}$ (1972) alimentaram ovinos com palha de cevada tratada pelo processo de imersão em soluções de soda $(\mathrm{NaOH})$, com concentrações de $0,5 \%$ a $4,0 \%$. Em relação à digestibilidade, observaram aumento linear até a concentração de $2 \%$.

Rexen; Thomsen ${ }^{26}$ (1976) trataram palhas por solução de $\mathrm{NaOH}$ a $30 \%$ e verificaram que as porcentagens de hemicelulose diminuíram enquanto as de celulose permaneceram constantes. Registraram aumento linear na digestibilidade in vitro da matéria orgânica (MO), com concentrações crescentes de alcali, mas as dosagens acima de $4 \%$ a $5 \%$ de $\mathrm{NaOH}$ não melhoraram a digestibilidade in vivo.

Molina et al. ${ }^{17}$ (1983) pulverizaram BCA com $\mathrm{NaOH}$ nas proporções de $2 \%, 4 \%$ e $6 \%$ da MS, encontrando uma diminuição linear na fração FDN de $93,6 \%$ para $72,7 \%$. Houve aumento do teor de minerais do BCA com emprego de maiores níveis de $\mathrm{NaOH}$.

Cabello et al. ${ }^{5}$ (1981) trataram o BCA com soda, em níveis de $4 \%$ a $12 \%$ da MS. Ao nível de $8 \%$ de $\mathrm{NaOH}$, digestibilidade in vitro foi igual a $80 \%$, enquanto para o BCA não tratado foi $20 \%$.

Da mesma forma, Ibrahin; Pearce ${ }^{9}$ (1983) observaram que os coeficientes de digestibilidade in vitro do BCA sem tratamento e tratado por $\mathrm{NaOH}$ a $9 \%$ foram de $32,8 \%$ e $57,1 \%$ respectivamente.

Vitti et al.$^{30}(1985)$ encontraram a degradabilidade ruminal do $\mathrm{BCA}$ aumentada quando adicionaram $5 \%$ de $\mathrm{NaOH}$ à silagem de bagaço, em relação à mesma silagem sem adição de $\mathrm{NaOH}$. $\mathrm{A}$ degradabilidade da silagem foi maior que a do bagaço fresco. 
SONKSEN. S.: LUCCI, C.S.; MELO'TrI, I. Degradabilidade "in situ” da fibra do bagaço de cana-de-açúcar tratado com soluçōex alcalinas e da proteína do farelo de algodão, em bovinos fistulados. Hraz. J. vet. Kes. anim. Sei., Säo Paulo. v.34, n.2, p.73-77. 1997.

Morgullis ${ }^{18}$ ( 1992) tratou o BCA que constituía $60 \%$ das dietas, com soluçōes de $\mathrm{NaOH} 2 \%$ (A), cinzas de madeira $30 \%$ (B) ou água (C) e verificou que os tratamentos alcalinos melhoraram sua degradabilidade ruminal e digestibilidade aparente. A degradabilidade da MS e da FDN, às 48 horas de incubax̧ĩo numinal foram: $75,14 \%$ e $74,01 \%$ para $A: 34,20 \%$ e 41,61 para $B$ e $24,26 \%$ e $35,72 \%$ para $C$, respectivamentc.

No tocaante à proteína do farelo de algodão, o NRC ${ }^{21}$ (1988) mostra que $41 \%$ do seu nitrogênio não é degradado no númen.

Quanto ao emprego de tamponantes, Kovacik et al..$^{12}$ (1986) estudaram os efeitos da suplementação de bicarbonato de sódio en dietas contendo $50 \%$ de volumoso e $50 \%$ de concentrados sobre o $\mathrm{pH}$ ruminal: os resultados mostraram que a porcentagem de tempo) (por 24 horas) em que o $\mathrm{pH}$ se manteve abaixo de 5,8 foi $70,4 \% ; 61,7 \% ; 44.7 \%$ e $15,4 \%$ para os niveis de $0 ; 1.5 \% ; 3,0 \%$ e $4.5 \%$, respectivamente.

Shimixda ef $a .^{27}$ (1989) fornoceram durante 8 meses, $100 \mathrm{~g}$ de bicartonato de sódio e $30 \mathrm{~g}$ de óxido de magnésio/animal/dia para vacas leiteiras alimentadas com dietas ricas em concentrados e pobres em volumosos e verificaram que o número de protozoários por mililitro de líquido ruminal aumentou significativarnente com a elevação do $\mathrm{pH}$ do rúmen. após o emprego de tampões.

Abe el al.' (1973) observaram que em dietas com altas quantidades de concentrados o gênero Entodinium $\mathrm{Sp}$ resiste ao pH ácido. Leng et al..$^{15}$ (1981) Valdez et al. ${ }^{2 y}(1977)$ e Leng; Preston ${ }^{16}$ (1976) indicaram populaçōes upicas de protozoxírios em animais que recebiam cana-deaçúcar em suas dietas.

O objetivo deste experimento foi avaliar o eteito da hidrólise alcalina sobre o valor nutritivo do BCA. e o emprego de tampx̃es em raçōes para ruminantes contendo $30 \%$ de $\mathrm{BCA}$ e $70 \%$ de concentrakos, estudando-se a degradabilidade ruminal da MS e FDN do BCA. e da MS e $\mathrm{PB}$ do farelo de algodão. Também foram realizadas contagens de protozuários de conteúdo do proventrículo, nox diversos tratamentos.

\section{MATERIAL E MÉTODOS}

Este trabalho foi conduzido na Faculdade de Medicina Veterinária e Zootecnia da Universidade de São Paulo, no Campus Administrativo de Pirassununga - SP. Foram comparados 4 tratamentos sendo: ABCA tratado com água mais concentrados contendo tampöes: B- BCA tratado com água mais concentrados; $\mathrm{C}$ - BCA tratado com soluçōes a $30 \%$ de cinzas de madeira mais concentrados; e D- BCA tratado com solução a $2 \%$ de hidróxido de sódio mais concentrados. Os concentrados. em todos os tratamentos, foram compostos por farelo de algodão e milho.

Os tampōes eram constituídos por bicarbonato de sódio (1.1\%) e óxido de magnésio $(0,7 \%)$; nos quatro tratamentos, o BCA ingnessiou na taxa constante de $(30 \%)$ ). sendo que $70 \%$ de concentrados (contendo milho. grãos c farelo de alg(xdão), formavam rações totais apresentando ak) redor de $11 \%$ de $\mathrm{PB}$. altendendo-se às exigências nutricionais reconendiadias pelo NRC'21 (1988) para bovinos de leite.

Foram utilizados quatro gamotes castrados, mestiços europeu/zebu. pesando em média $150 \mathrm{~kg}$. provides de cânulas ruminais, para execução de técnica dexicrita por Orskov et al. ${ }^{22}$ ( 1980$)$, para sacos de náilon in situ.

O tratamento do BCA era feito: a) por solução de soda (2\% pesol volume); b) por solução de cinzas de madeira ( $30 \% \mathrm{p} / \mathrm{v})$, feita com cinzas de olaria previamente peneiradas; c) por água.

Obagaço de cana-de-açúcar continha originarriamente $50 \%$ de MS e sua imersĩo era feita nas soluções por 6 horas.

As análises bromatológicas do BCA e do farelo de algodão foram feitas segundo $\mathrm{AOAC}^{2}$ (1965) e os teores de FDN e FDA foram calculados de acordo com Goering; Van Soest ${ }^{8}$ (1970).

Odelineamento estatístico foi em quadrado latino, com 4 animais. e subperíodos de 21 dias cada. As comparações entre médias foram feitas pelo teste de Tukey ( $\mathrm{p}<0,05$ ), segundo Snedecor; Cochran ${ }^{28}$ (1967). Os tempos de incubação para o BCA foram $0 ; 6 ; 12 ; 24 ; 48 ; 72$ e 96 horas e para o fanelo de algodão: $0 ; 1$ 1/2:3.6; 12 e 24 horas.

Foi usado um marcador de fase líquida - PEG 4000 - para cálculo do num-over com retiradas de líquido numinal às $0 ; 1 ; 3 ; 6 ; 9 ; 12$ e 24 horas; essas amostragens prestaram-se também para contagem de protozóários e determinação do $\mathrm{pH}$.

\section{RESULTADOS E DISCUSSÃO}

A Tab.I contém a composição química das amostras: de BCA tratado com água ( $\mathrm{BCA}+\mathrm{H} 20$ ); por soluçēo ) de cinzass de madeira a $30 \%$ (BCA + cinzas); por solução de $\mathrm{NaOH}$ a $2 \%$ (BCA + Soda) e do farelo de algodão e de fubá de milho; bem como das rações utilizadas nos tratamentos:

O BCA do prasente trabalho apresentou composição química dentro dos padröes encontrados por Lamas el al. ${ }^{14}$ (1979); Kunar et al!.3 ( 1982); Ibrahin; Pearce" (1983); Molina el al. ${ }^{17}$ (1983) e o NRC'2l (1988).

$\mathrm{O}$ teor de MO diminuiu no tratamento com soda e em menor escala naquele com cinzas. valores esses que estäo de acordo com os de Cammona; Greenhalgh' (1972), cuja explicax̧ão seria a perda de ENN.

A FB do BCA tratado com $\mathrm{NaOH}$, bem como do tratado por cinzas, diminuiu em relação ao tratanento testemunha (B). No entanto. Carmona; Greenhalgh ( 1972) encontraram aumento do teor de FB cm matérias fibrosas (palhas) tratadas com soda.

O toor de MM foi muito alto (16,8\%) no tratamento com soda; este fato, segundo Rexen; Thomsen ${ }^{26}$ (1976), pxxkeria conduzir ao aumento da ingestão de água, para eliminação dox ions Na e acarretaria também um volume maior de urina excretádo.

Outro fato observado neste trabalho foi a diminuição da FDN com a aplicação de soda (em relação ao tratamento testemunha), enquanto que o toor da FD sofreu pouca alteração demonstrando que a hemicelulose é que foi perdida no tratamento por soda.

A Tab. 2 apresenta as taxas de degradabilidade ruminal da MS e FDN do BCA, em porcentagens; os valores de a b e c da fómmula de Orskov; Mc Donald ${ }^{77}$ (1979) e ainda da degradabilidade efetiva (p), de acordo com $A R F C^{2}(1992)$, adotando-se taxa de $0,05 / \mathrm{h}$ para o efluxo de matéria ruminal (r).

Os resultados obudos com a MS do BCA acusiun melhoria na sua degradabilidade ruminal com aplicaz̧ão de $\mathrm{NaOH}$, em relação aos demais tratamentos, estando de acordo com os resultados de Jackson ${ }^{10}$ (1977); Morris: Bacon 19 (1977); Klopfenstein" (1978); Chesson; Orskov" (1984); Cabello et al. (1981); Vitti et al." (1985) e Morgullis's (1992). As cinzas melhoraram a degradabilidade da MS do BCA somente às 96 horas de incubação, em relação ax BCA testemunha. Morgullis ${ }^{18}$ (1992) encontrou taxas de degradação ruminal de 75,0\% e 34,0\% para o BCA 
tratado com soda e cinzas, respectivamente, às 48 horas de incubação, compiradas às taxas de $50.4 \%$ e $29.2 \%$ no presente caso. Aquele autor. no entanto. empregou raçioses com $60 \%$ de BC.A.

$O$ tratamento por soda a $2 \%$ implicou em maiores taxas de degradação da fíbra do BCA. às 72 e 96 horas de incubação. Nem o tratamento do BCA por cinzats. nem o emprego de tampöes nos concentrados, mostraram efcitos estatisticamente significativos:

As rações continham elevada proporção de alimentos concentrados. o que deveria propiciar melhores resultados com o emprego de tanpōes. (Kovacik ct al. ${ }^{12}$ (1986).)

Morgullis $^{18}$ (1992) encontrou $74,0 \%$ e $41,0 \%$ de taxas de degradabilidade ruminal. às 48 horas de incubação, para FDN, cm dietas com $60 \%$ de $\mathrm{BCA}$ tratado por $\mathrm{NaOH}$ e cinzas de madeira. respoctivamente. No presente cax), com $30 \%$ de BCA. os resultados foram $40.49 \%$ $27.87 \%$.

A Tah. 3 apresenta taxas de degradabilidade da MS e P'B do farelo de algodão, em porcentagens. para os diversoss tempos de incubação; "apresenta taunbémos valores de a bec. da fómnula de Orskov; McLonald" (1979), bem como o valor da degradabilidade efetiva (p). de acordo com $\operatorname{ARFC}^{\prime}(1992)$.

Não (xorreram diferenças significativas entre tratamentos. A degradabilidade da PB. entre $50 \%$ e $62 \%$, foi compatível com os resultaldos apresentados pelo NRC ${ }^{21}$ (1988), que assume $59 \%$.

A Tab. 4 mostra valones de volume ruminal, mum-over do líquido ruminal. número total de protozoários por mililitoro de líquido ruminal eo $\mathrm{pH}$ do liquido do rúmen.

Otum-orer do líquido numinal foi significativamente maior para o tratamento com soda, e o com cinzas, intermediário. Provavelmente isso ocorreu pela maior ingestão de água necessária para eliminar a quantidade excessiva de $\mathrm{NaOH}$ do tratamento D (Rexen; Thomsen ${ }^{26}$, 1976). Contudo, o tratamento A, com bicarbonato de sódio, não apresentou aumento do tum-over, em relação ao B (testemunha). O emprego conjunto do bicartonato de sódio e do óxido de magnésio não al tenou os resultados de fum-over, como aconteceu com Peirce et al..$^{-5}$ (1983).

O número total de protozoários foi diferente para toxdos os tratamentos. Shimada et al..$^{27}$ (1989) encontraram aumento significativo no número de protozoários/ml e pH do líquido ruminal. após o uso de tampōes. Neste experimento, os valores de $\mathrm{pH}$ não diferiram entre tratamentos. Dentre os protozoúrios, o gênero Entodinium $\mathrm{Sp}$. foi o mais abundante, representando $77.7 \% ; 89.4 \% ; 86.1 \%$ e $95.4 \%$ do número total de protozoúrios. para $\mathrm{A}, \mathrm{B}, \mathrm{C}$ e $\mathrm{D}$, respectivamente, o que está de acordo com os resultados de Abou Akkada et al. (1966).

Tabela 1

Resultados das análises bromatológicas dos ingredientes das raçôes completas e do FDN e FDA, com base na matéria seca, em porcentagem. Pirassunungo - SP, 1990.

\begin{tabular}{c|c|c|c|c|c|c|c|c|c}
\hline Variáveis & MS & MO & PB & FB & EE & MM & ENN & FDN & FDA \\
\hline BCA água & 30,0 & 98,9 & 2,30 & 54,17 & 1,31 & 1,09 & 41,13 & 96,57 & 67,62 \\
BCA cinzas & 25,0 & 93,2 & 1,94 & 51,39 & 1,92 & 6,77 & 37,98 & 75,94 & 66,96 \\
BCA soda & 20,0 & 83,1 & 1,58 & 49,61 & 14,22 & 16,84 & 30,75 & 91,58 & 66,15 \\
F. alg. & 89,8 & 92,8 & 46,00 & 14,43 & 2,66 & 7,22 & 29,69 & \\
F. milho & 85,0 & 98,6 & 10,20 & 2,35 & 4,58 & 14,41 & 81,46 & \\
Trat.A & 69,4 & 93,15 & 10,84 & 14,77 & 3,26 & 6,85 & 64,28 & \\
Trat.B & 69,0 & 92,7 & 11,83 & 12,52 & 2,1 & 7,28 & 66,20 & \\
Trat.C & 67,5 & 93,0 & 10,04 & 20,74 & 3,38 & 7,02 & 58,82 & & \\
Trat.D & 66,0 & 93,5 & 9,74 & 16,63 & 3,56 & 6,48 & 63,59 &
\end{tabular}

Tabela 2

Taxas de degradabilidade da MS e FDN do BCA, nos diferentes tempos de incubaçāo, em porcentagens, valores de a. b e c, segundo Orskov; McDonald $^{23}$ (1979) e degradabilidade efetiva (p), de acordo com ARFC ${ }^{3}$ (1992). Pirassununga -SP, 1990.

\section{Tratamentos - MS}

\begin{tabular}{|c|c|c|c|c|c|c|c|c|}
\hline $\begin{array}{l}\text { Horas de } \\
\text { incubação }\end{array}$ & $\begin{array}{c}A \\
\text { água + } \\
\text { tampöes }\end{array}$ & $\begin{array}{c}\text { B } \\
\text { água }\end{array}$ & $\begin{array}{c}\mathrm{C} \\
\text { cinzas }\end{array}$ & $\begin{array}{c}\text { D } \\
\text { soda }\end{array}$ & $\begin{array}{c}\mathrm{A} \\
\text { água + } \\
\text { tampōes }\end{array}$ & $\begin{array}{c}\text { B } \\
\text { água }\end{array}$ & $\begin{array}{c}\text { C } \\
\text { cinzas }\end{array}$ & $\begin{array}{c}\mathrm{D} \\
\text { soda }\end{array}$ \\
\hline $\begin{array}{c}0 h \\
6 h \\
12 h \\
24 h \\
48 h \\
72 h \\
96 h \\
a \\
b \\
c \\
p\end{array}$ & $\begin{array}{c}4,7 \\
6,4 b \\
10,3 b \\
20,2 b \\
27,6 b \\
34,9 b \\
38,3 b \\
3,4 \\
42,8 \\
0,01 \\
14,7\end{array}$ & $\begin{array}{c}5,5 \\
6,0 b \\
8,8 b \\
15,5 b \\
24,5 b \\
26,3 b \\
26,0 \mathrm{c} \\
3,5 \\
26,0 \\
0,02 \\
12,4\end{array}$ & $\begin{array}{c}5,7 \\
7,4 b \\
14,2 b \\
18,3 b \\
29,2 b \\
36,2 b \\
39,7 b \\
5,0 \\
45,0 \\
0,01 \\
15,3\end{array}$ & $\begin{array}{c}13,0 \\
21,4 a \\
25,8 a \\
34,0 a \\
50,4 a \\
61,5 a \\
66,5 a \\
13,7 \\
67,9 \\
0,01 \\
30,1\end{array}$ & $\begin{array}{c}5,3 \\
7,6 a \\
13,0 \\
22,2 \\
32,0 \\
39,1 b \\
41,8 b \\
3,9 \\
44,6 \\
0,02 \\
16,6\end{array}$ & $\begin{array}{c}6,9 \\
7,0 \mathrm{a} \\
11,4 \\
18,7 \\
28,5 \\
32,1 \mathrm{~b} \\
34,1 \mathrm{~b} \\
4,8 \\
34,4 \\
0,02 \\
15,0\end{array}$ & $\begin{array}{c}3,5 \\
3,6 b \\
11,0 \\
14,5 \\
27,8 \\
36,6 b \\
41,8 b \\
2,0 \\
65,0 \\
0,01 \\
12,9\end{array}$ & $\begin{array}{c}4,5 \\
5,4 a b \\
10,6 \\
20,7 \\
40,4 \\
55,9 a \\
61,4 \\
1,3 \\
104,48 \\
0,01 \\
-\end{array}$ \\
\hline
\end{tabular}

$(* *)=$ letras diversas na mesma linha indicam diferenças significativas $(p>0,01)$ entre tratamentos, pelo teste de Tukey. 


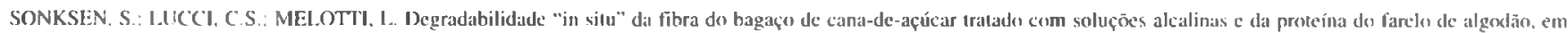
buvinos tistulados. Braz. J. vet. Res. a nim. Sci.. Sāo Paulo, v.34, n.2. p.73-77. 1947

Tabela 3

Taxas de degradabilidade da MS e PB do farelo de algodōo, nos diversos tempos de Incubaçāo, em porcentogens. Valores de a, b e c, segundo Orskov: McDonald²3 (1979), e degradabilidade efetiva (p), de acordo com ARFC ${ }^{3}$ (1992). Pirassununga - SP, 1990.

\begin{tabular}{c|c|c|c|c|c|c|c|c}
\multicolumn{4}{c|}{ Tratamentos - MS } & \multicolumn{4}{c}{ Tratamentos - PB } \\
\hline Horas de incubação & $\begin{array}{c}\mathrm{A} \\
\text { água + } \\
\text { tampões }\end{array}$ & $\begin{array}{c}\mathrm{B} \\
\text { água }\end{array}$ & $\begin{array}{c}\mathrm{C} \\
\text { cinzas }\end{array}$ & $\begin{array}{c}\mathrm{D} \\
\text { soda }\end{array}$ & $\begin{array}{c}\mathrm{A} \\
\text { agua + } \\
\text { tampóes }\end{array}$ & $\begin{array}{c}\mathrm{B} \\
\text { água }\end{array}$ & $\begin{array}{c}\mathrm{C} \\
\text { cinzas }\end{array}$ & $\begin{array}{c}\mathrm{D} \\
\text { soda }\end{array}$ \\
\hline O h & 19,7 & 17,7 & 18,6 & 20,8 & 3,1 & 5,9 & 4,8 & 14,0 \\
$11 / 2 \mathrm{~d}$ & 30,9 & 33,1 & 31,8 & 32,6 & 22,6 & 25,5 & 21,4 & 22,5 \\
$3 \mathrm{~h}$ & 34,7 & 36,6 & 34,5 & 35,8 & 26,4 & 30,4 & 27,1 & 26,2 \\
$6 \mathrm{~h}$ & 40,3 & 39,2 & 40,2 & 39,0 & 32,4 & 34,2 & 34,4 & 32,3 \\
$12 \mathrm{~h}$ & 53,9 & 53,0 & 52,0 & 51,2 & 46,3 & 47,3 & 47,7 & 45,3 \\
$24 \mathrm{~h}$ & 64,2 & 58,2 & 62,4 & 64,7 & 60,3 & 49,3 & 59,7 & 62,5 \\
a & 21,8 & 20,9 & 21,6 & 24,2 & 12,3 & 8,5 & 8,2 & 15,9 \\
b & 46,8 & 37,7 & 43,6 & 49,1 & 54,2 & 39,8 & 52,5 & 66,4 \\
c & 0,09 & 0,15 & 0,10 & 0,07 & 0,08 & 0,24 & 0,12 & 0,05 \\
d & 35,4 & 49,2 & 51,1 & 52,7 & 46,6 & 41,6 & 46,0 & 48,7
\end{tabular}

Tabela 4

Efeitos dos tratamentos no volume ruminal, na taxa de reciclagem rumlnal da fase líquida (turn-over), na taxa de fluxo (volume ruminal x turn-over) no número tołal de protozoários e no pH ruminal ("). Pirassununga - SP, 1990.

Tratamentos

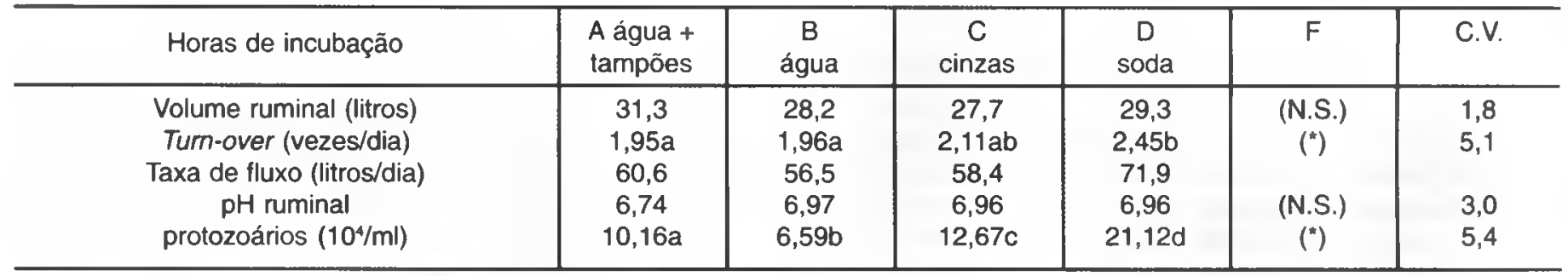

$\left(^{*}\right)$ Letras diversas na mesma linha significam diferenças estatísticas $(p<0,05)$.

\section{CONCLUSÕES}

Nas condiçōes do presente trabalho as seguintes conclusões padem ser tiradas:

1) O tratamento do BCA por $\mathrm{NaOH}$ a $2 \%$ causou aumento significativo nas taxas de degradação da MS em todos os tempos de incubação estudados e de fibra (FDN). nos tempos de 42 e 96 horas.

2) As taxas de degradação da MS e PB do farelo de algodão não sofreram interferência dos tratamentos experimentais.

3) O turn-over ruminal e o número de protozoários/ml de líquido ruminal foram maiores no tratamento do bagaço por soda.

\section{SUMMARY}

Sugar cane bagasse (SCB) was immersed either in water (B), or in sodium hydroxide solution $2 \%$ (D), or in wood ashes solution $30 \%$ (C), or was supplemented with buffers in the concentrate mixture: (sodium bicarbonate, 1,1\% and magnesium oxide $0,7 \%$ of ration dry matter (DM)), to evaluate this residue for ruminant feeding, receiving diets with $30 \%$ of DM as SCB. Four rumen canulated steers were used to estimate ruminal degradability rates of DM and neutral detergent fiber (NDF) of the SCB in situ, as well as DM and CP degradabilities of the cotton seed meal, using a $4 \times 4$ change-over design. Results showed higher DM degradabilities for SCB or treatment $\mathrm{D}$, and also for NDF, but in $72 \mathrm{~h}$ and $96 \mathrm{~h}$ of incubatio times. Cotton seed meal presented similar rates of degradabilities among all treatments. Treatment $D$ was efficient to improve SCB rumen degradability.

UNITERMS: Digestibility; Cottonseed meal; Sugarcane bagasse; Alkaline; Solutions; Bovine. 


\section{REFERÊNCIAS BIBLIOGRÁFICAS}

1-ABE. M.: SHIBUI, H.; IRIKI, T.: KUMENO, F. Relation between diet and protozoal population in the rumen. British Journal of Nutrition. London. v.29, n.2, p. 197-202, 1973.

2-AOAC - ASSOCIATION OF OFFICIAI. AGRICULTURAL CHEMIST. Official methods of analysis. n.13. ed. Washingion. AOAC. 1985.

3-AIRC - AGRICULTURAI. AND FOOD RESEARCH COUNCII. Nutritive requeriments of ruminant animals: protein. Nutrition Abstracts and Reviews. (Series B), v.62, n.12, p. 787-835, 1992.

4-BOIN, C.: MATTOS, W.R.S.: D ARCE. R.D. Cana-de-açúcar e seus subprodutos na alimentação de ruminantes. In: PARANHOS. S.B. Canade-açúcar: cultivo e utilização. Campinas, Fundação Cargill. 1987. p. 805-50.

5-CABEI.L.O, A.: CONDE. J.: OTERO. M.A. Prediction of the degradability of sugarcane cellulosic residues by indirect methods. Biotechnology and Bioengineering, v.23, p.2737-45, 1981 .

6. CARMONA. F.: GRFENHALGH. J.F.D. The digestibility and acceptability to sheep of chopped or milled barley straw soaked or sprayed with alkali. Journal of Agricultural Science. Cambridge, v.78. n.3. p.477-85, 1972.

7-CHESSON, A.: ORSKOV, E.R. Microbial degradation in the digestive tract. In: Sudstol. F; Owen, E. Straw and other fibrous by-products as feed. Amsterdam, Elsevier. 1984, p.305-34

8-GOERING. H.K.: VAN SOEST. P.J. Forage fiber analysis Washington. Agricultural Research Service, 1970. 19p. (Agricultural Handbook. II. 379).

9-IBRAHIN. M.N.M.; PEARCE. G.R. Elfects of chemical pretreatment on the composition and in virro digestibility of crop by-products. Agricultural Wastes, v.5, n.3. p.135-56, 1983.

10-JACKSON, M.G. Review aricle: the alkali treatment of straws. Animal Feed Science and Technology. v.2, n.2, p. 105-30, 1977.

II-KLOOPFENSTEIN. T.J. Chemical treatment of crop residues. Journal of Animal Science. v.46, n.3. p.841-8, 1978.

12-KOVACIK. A.M; L.OERCH, S.C.; DEHORITY, B.A. Effect of supplemental sodium bicarbonate on nutrient digestibilities and ruminal $\mathrm{pH}$ measured continuosly. Journal of Animal Science, v.62, n.I, p.226-34, 1986.

13-KUMAR, A.: VERMA. D.N.; DASS, R.S.; SINGiH. U.B. Effecl of concentration and period of amonia treatment on the chemical composition and nutritive values of sugar cane bagasse. Indian Journal of Nutrition and Dietetics. v. 19, p.381-8, 1982.

14-L.AMAS, G.L.; SHIMADA, A.S.; RUELA, S.C.; ZUNGA, H.M. Estudio del valor alimenticio de subproductos de la cana de azucar con bovinos en corral. Tecnica Pecuaria en Mexico, n. 36, p.59-64, 1979.

15-LENG. R.A.; GILI.. M.; KEMPTON, T.J.; ROWE. J.B.: NOLAN. J.V.: STACHIW, S.J.; PRESTON, T.R. Kinetics of large ciliate protozoa in the rumen of cattle given sugar cane diets. British Journal of Nutrition. v. 46. n.2. p.371-84, 1981

16-LENG. R.A.; PRESTON, T.R. Sugar cane for cattle production: present constraints. perpectives and research priorities. Tropical Animal Production, Santo Domingo, v.l. n.l. p. I-22, 1976.

17-MOLINA. E.; BO7.A. J.; ACiLILERA, J.F. Nutritive value for ruminants of sugar cane bagasse ensiled after spray treatment with different levels of $\mathrm{NaOH}$. Animal Feed Science and Techonology, v.9. n. 1, p.1-17, 1983.

18-MORGULLIS, S.C.F. Degradabilidade ruminal e digestibilidade aparente do bagaço de cana-de-açúcar tratado por soluções alcalinas de cinzas de madeira e hidróxido de sódio. São Paulo. 1992. 72 p. Dissertação (mestrado). Faculdade de Medicina Veterinária e Zootecnia. Universidade de São Paulo.

19-MORRIS. J.E.; BACON. J.S.D. The fate of acetyl groups and sugar components during digestion of grass cell walls in sheep. Journal of Agricultural Science, Cambridge, v.89. n.3, p.327-40. 1977.

20-NICHOL.SON, J.W.G., 1984, apud MORGULL.IS. S.C.F., 1992, p.3.

2I-NRC - NATIONAL RESEARCH COUNCIL. Nutrient requirements of dairy cattle. Washington, NRC, 1988. 157p.

22-ORSKOV. E.R.; HOVELL, F.D.D.; MOUI.D. F. Uso de la Tecnica de bolsa de nylon para las valuacion de los alimentos. Production Animal Tropical, v.5. n. 3, p.213-33, 1980 .

23-ORSKOV, E.R.: MCDONAL.D. D. The extimation of protein degradability in the rumen from incubation measurements weighed according to rate of passage. Journal of Agricultural Science, v.92, n.2, p.499-503, 1979.

24-PATURAL. J.M. By-Products of the sugar cane indusiry. Amsterdam. Elsevier, 1981. p.305-34.

25-PEIRCE. S B.: MULI.ER. I..D.: HARPSTER. H.W. Influence of sodium bicarbonat and magnesium oxide on digestion and metabolism in yearking beef steers abruptly changed from high forage to high energy diets. Journal of Animal Science, v.57, n.6. p.1561-7, 1983.

26-REXEN, F; THOMSEN, K.V. The effect on digestibility of a new technique for alkali treatment of straw. Animal Feed Science and Technology, v.l. n.1. p.73-83, 1976 .

27-SHIMADA, Y.; HAGOKI. E.; NHIDA, S. Effect of sodium bicarbonate and magnesium oxide on cows with milk fat depression in several dairy herds. Japanese Journal of Veterinary Science. v.51, n.21. p.373-9. 1989.

28. SNEDECOR. G.W.; COCHRAN, W.G. Statistical methods, 6. ed.. Ames. The lowa State University Press, 1967. 593p.

29. VALDEZ, R.E.: ALVAREZ. F.C.: HERREIRO. H.M.: GUERRA. F.: LOPEZ. J.; PRIEGO. A.; BLACKBURN. T.H: LENG. L..A.; PRESTON, T.R. Rumen functions in cattle given sugar cane. Tropical Animal Production, v.2. n.3, p. 260-72, 1977.

30. VITTI. D.M.S.S; ABDALI.A, A.I.; LOBAO. A.O.; SII.VA FII.HO, J.C. Tratamento químico, físico e biológico do bagaço de cana-de-açúcar. Comunicações Científicas da Faculdade de Medicina Veterinária e Zootecnia, v.9, n.2, p. I.39-42, 1985.
Recebido para publicação: 05/04/95 Aprovado para publicação: 23/07/96 